


\section{El peor cuento \\ antirrealista de Borges:}

El Sur

\section{Santiago Viscaíno*}

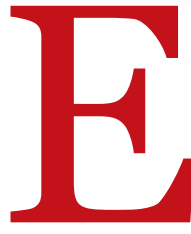

n "El escritor argentino y la tradición", dice Borges que "lo verdaderamente nativo suele y puede prescindir del color local". Así, su literatura no se desentiende del papel que sus detractores advertían en la formación de la identidad argentina y latinoamericana, sino que posibilita la construcción, desde el proceso de sublimación o la "sublimación en proceso", como la llama Alejandro Moreano ${ }^{2}$, de lo individual hacia lo absoluto, y viceversa.

Santiago Vizcaíno Armijos (Quito, Ecuador, 1982) es Licenciado en Comunicación y Literatura por la Pontificia Universidad Católica del Ecuador. Cursó la Maestría en Estudios de la Cultura, Mención Literatura Hispanoamericana, en la Universidad Andina Simón Bolívar. Textos suyos se han publicado en las revistas Letras del Ecuador, Rocinante, Ruido Blanco, Casa de las Américas (Cuba), Connotation Press (EEUU), Punto de Partida (México), entre otras. Su primer libro de poesía, Devastación en la tarde, recibió el Premio Nacional de Literatura en 2008 por parte del Ministerio de Cultura. Asimismo su libro de ensayo Decir el silencio, en torno a la poesía de Alejandra Pizarnik, que obtuvo el segundo lugar en esa categoría. Recibió el Segundo Premio Pichincha de Poesía 2010 por su libro En la penumbra y una mención particular en la XXVI Edición del Premio Mundial Nósside de poesía. 
1 Jorge Luis Borges, Páginas escogidas, La Habana, Casa de las Américas, 2006, p. 124

2 Alejandro Moreano, "Borges, vanguardia y modernidad latinoamericana", Quito, UASB, mimeografiado.

3 Ismael Rivera L., "Borges: un visión latinoamericana (tradición y traición)", Proyecto Patrimonio 2010, 2010-12-02,

http://www.letras.s5.com/ir181 10.htm

4 Roberto Fernández Retamar, en J.L.Borges, Páginas escogidas, op. cit,

5 Citado por Juan Gustavo Cobo Borda, "Borges: el duelo original", Centro Virtual Cervantes, 2010-12 02, en http://cvc.cervantes.es/actcult/borges/intro/ default2.htm
No es ninguna novedad decir que Borges es un escritor universal y, por ello mismo, profundamente latinoamericano. El conflicto radica en la comprensión de un fenómeno complejo donde la identidad misma se ficcionaliza hacia una forma estética donde los géneros y las ciencias están imbricados. Su literatura se inserta dentro de la dialéctica propia de Latinoamérica, donde no es posible la construcción de grandes sistemas filosóficos.

Desde el siglo XIX, la literatura latinoamericana es consciente de su papel en la construcción de la identidad; su ideal filosófico en ese sentido es preponderante. En Borges, en cambio, esa necesidad se transfigura y adopta una heterogeneidad que la trasciende y la contiene. Lo paradójico es que dicha heterogeneidad parte de la necesidad de crear un orden estético absoluto; "podríamos decir que lo latinoamericano de Borges radicaría, no en sus temáticas, sino en la forma de abordarlas". ${ }^{3}$

Sabemos, como dice Fernández Retamar, que "Borges profesa un antirrealismo militante", ${ }^{4}$ pero que no dejó de escribir cuentos realistas donde profundiza su idea particular sobre la identidad en un diálogo con su tradición cultural. Así, vemos en El Sur, el que considera su mejor cuento, cómo el proceso de transculturación, como lo llama Ángel Rama, permite reforzar la propia cultura a partir de la permeabilidad de lo foráneo. Este continente transculturado no solo que "sincretiza" la tradición con su idea de lo propio, sino que configura una nueva forma de ser particular que en Borges se tematiza, pero no como una figura latinoame- ricanista en franca necesidad política, sino en un diálogo paródico, irónico, donde él mismo es objeto de interrogante metafísica.

Dice Borges, entrevistado por James Irby:

El Sur es un cuento bastante autobiográfico, al menos en sus primeras páginas. El abuelo de Dahlmann era alemán; mi abuela era inglesa. Los antepasados criollos de Dahlmann eran del sur. Los míos, del norte. El abuelo materno de Dahlmann peleó contra los indios y murió en la frontera de Buenos Aires; el mío paterno hizo lo mismo, pero murió en la revolución del $74 .^{5}$

De allí que en El Sur la idea propia de lo latinoamericano se trasluzca bajo los enmascaramientos de la literatura, pero no deja de advertir una idea clara y superlativa de Borges: se es argentino por elección, es decir, que la idea de patria es una decisión. Por ello la idea romántica de morir como los grandes héroes, los que construyeron la idea de nación, no es descabellada, sino que introduce el conflicto mismo de la identidad.

En ese sentido Dhalmann simboliza la fractura entre el intelectual y el hombre de acción, cuya escisión manifiesta ya Borges en el Poema conjetural:

\footnotetext{
Yo que anhelé ser otro, ser un hombre de sentencias, de libros, de dictámenes, a cielo abierto yaceré entre ciénegas; pero me endiosa el pecho inexplicable un júbilo secreto. Al fin me encuentro con mi destino sudamericano. (Borges, 2006: p. 41)
} 
Es éste el encuentro que al final escoge Dhalmann, la posibilidad onírica de una muerte épica. No es gratuito que Borges se decante por el cuento como género narrativo por excelencia, además del ensayo, porque le permite la cercanía con la tradición oral, con las masas que han de asesinar a su personaje dentro del ideal heroico ya imposible en su época, porque a "la realidad le gustan las simetrías y los leves anacronismos" (Borges, 2006: p. 372).

Esta dualidad de Dhalmann, además, le permite jugar con su idea del doble: "Mañana me despertaré en la estancia, pensaba, y era como si a un tiempo fuera dos hombres: el que avanzaba por el día otoñal y por la geografía de la patria, y el otro, encarcelado en un sanatorio y sujeto a metódicas servidumbres" (Borges, 2006: p. 375). Por un lado, la estancia supone la libertad, pero solo como parte de su ser romántico, que lo ha de sepultar; y, por otro, la ciudad, que entraña la idea de opresión, donde el Borges lleno de libros ha de morir.

Allí el cuento se desdobla, porque no sabemos si Dhalmann en efecto asiste a su encuentro con la muerte en la pampa o es un sueño: "La soledad era perfecta y tal vez hostil, y Dhalmann pudo sospechar que viajaba al pasado y no sólo al Sur" (Borges, 2006: p. 374). En efecto es un viaje al pasado, a un remoto pasado glorioso que ya no reconoce del todo.

Sí, es un sueño, un sueño más realista que esa idea de servidumbre de la ciudad. Y es ese Sur, ese punto cardinal que no existe, donde existía el gaucho "oscuro, chico y reseco, y estaba como fuera del tiempo, en una eternidad” (Borges, 2006: p. 375), el que le ofrece la posibilidad del honor de batirse con unos parroquianos con la daga de ese gaucho que ha vislumbrado, y sentir que ese Sur era suyo. Una muerte ideal que plantea la imposibilidad de encuentro con lo propio, es decir, que aquella muerte como un gaucho es también metáfora de la ilusa idea de nación.

A Borges, como a Dhalmann, le hubiera gustado esa gloria épica, pero esa necesidad significa reconocer que lo propio es ajeno y viceversa, y allí se centra el espíritu latinoamericano: en una entelequia de lo propio. La idea de nación no es más que el sueño de un hombre enfermo que se niega a morir sin identidad.

\section{Bibliografía}

- Borges, Jorge Luis, Páginas escogidas, La Habana, Casa de las Américas, 2006.

- Cobo Borda, Juan Gustavo, "Borges: el duelo original", Centro Virtual Cervantes, 2010-12-02, en http://cvc.cervantes.es/actcult/borges/intro/default2.htm

- Moreano, Alejandro, "Borges, vanguardia y modernidad latinoamericana", Quito, UASB, mimeografiado.

- Rivera L., Ismael, "Borges: una visión latinoamericana (tradición y traición)", Proyecto Patrimonio 2010, 2010-12-02, en: http://www.letras.s5.com/ir181110.html 